\title{
Markovian Geology Prediction Approach and its Application in Mountain Tunnels
}

\author{
Zhenchang Guan ${ }^{1}$, Tao Deng ${ }^{1}$, Saizhao $\mathrm{Du}^{1}$, Bo Li ${ }^{2}$, Yujing Jiang ${ }^{2 *}$ \\ ${ }^{1}$ College of Civil Engineering, Fuzhou University, Fuzhou 350108, China \\ ${ }^{2}$ Department of Civil Engineering, Nagasaki University, Nagasaki 852-8521, Japan
}

\section{Introduction}

Tunneling is characterized by high degree of uncertainty, more so than in many other areas of civil engineering. Geological uncertainty is the primary source of uncertainty in the construction of mountain tunnels. The ground conditions are never known well prior to excavation, and must be inferred based on general information describing the geologic formations nearby as well as on location-specific observations provided by subsurface explorations. Many studies, including hard methods and soft methods, have been developed to mitigate the geological uncertainties in tunnel projects. Hard methods, such as subsurface boring, pilot drilling and advanced geophysical prospecting, utilize in-site equipment to obtain geological information in some specific locations along the tunnel alignment. In the contrast, several geology prediction approaches, known as soft methods, are developed to complement the results from hard methods. They are summarized into four categories as follows.

The time series approach performs direct analysis on some system variables that change over time, so as to uncover hidden trends and patterns from the time-ordered observations (Jeon et al, 2005). Large amounts of information (e.g. the deformations of surrounding rock mass) are necessary to uncover the processing of underlying variables (e.g. rock mass rating ahead of face). The neural networks approach is also suitable for the prediction of ground conditions, because it can analyze non-linear trends and patterns hidden in geologic data through machine learning (Alimoradi et al, 2008; Lau et al, 2010). Several types of neural networks, including back-propagation perception networks, support

\footnotetext{
* Corresponding author.

Address: Bunkyo Machi 1-14, Nagasaki 852-8521, Japan

Email: jiang@nagasaki-u.ac.jp
} 
vector machine networks and radial basis function networks, have been widely used as prediction tools in many geology related engineering. The Markov process approach regards each single geological parameter as a discrete-state continuous-space Markov process (Ioannou, 1987; Ioannou, 1989; Felletti and Beretta, 2009). Based on the geological information revealed in some specific locations, the state probability of each single geological parameter and further the state probability of ground condition along the tunnel alignment are inferred through Bayesian updating and transition probability calculation (Ching and Chen, 2007; Miranda et al, 2009). The hybrid approach, which combines these three approaches mentioned above with other mathematical and computational tools, is also developed to deal with some specific geology prediction tasks (Leu and Adi, 2011; Leu and Adi, 2011).

The Markovian geology prediction approach is adopted in this article to dynamically predict the geology condition along the tunnel alignment, because it has solid mathematical foundation and is relatively easier to be handled in practice. The methodology of Markovian geology prediction approach, which is based on Ioannou (1987), is comprehensively reviewed in Section 2. The application to the Chuangshi Tunnel project is carefully studied in Section 3, where some limitations and improvements are also presented. Some comments and conclusions are then summarized in Section 4.

\section{Methodology of Markovian geology prediction approach}

\subsection{Single geological parameter as a continues-space discrete-state Markov process}

The spatial variability of a single geologic parameter (e.g. rock type) can be described by its transitions in or out of parameter states (e.g. granite, limestone, schist, etc.), each of which has a certain length of persistence. Therefore, one single geologic parameter can be regarded as a random process $X(t)$, whose state probability is a function of location $t$. In practice, Markov process with its distinguishing characteristic of one-step memory is often employed to describe this random process. The Markovian assumption of one-step memory can be expressed as following:

$$
P\left[X\left(t_{i+1}\right)=x_{i+1} \mid X\left(t_{i}\right)=x_{i}, X\left(t_{i-1}\right)=x_{i-1}, \ldots\right]=P\left[X\left(t_{i+1}\right)=x_{i+1} \mid X\left(t_{i}\right)=x_{i}\right]
$$

where $t_{i+1}, t_{i}, t_{i-1}, \ldots$ are the locations along the tunnel alignment in sequence, and $x_{i+1}, x_{i}, x_{i-1}, \ldots$ are the outcomes of corresponding random variable of $X\left(t_{i+1}\right), X\left(t_{i}\right), X\left(t_{i-1}\right)$ at those locations.

The continuous-space discrete-state Markov process for a single geological parameter is completely determined by 
the transition intensity matrix $\mathbf{A}$ :

$\mathbf{A}=\left[a_{i j}\right], \quad$ where $a_{i j}=\left\{\begin{array}{ll}-c_{i} ; & i=j \\ c_{i} p_{i j} ; & i \neq j\end{array} \quad i, j=1,2, \ldots n\right.$

In the above, transition probability $p_{i j}$ is the probability that the next state of $X$ will be $j$ given the present state is $i$. Transition intensity coefficient $c_{i}$ is the expected distance over which the parameter $X$ will remain in a particular state $i$, and $c_{i}$ follows an exponential distribution under the Markovian assumption of one-step memory.

The probabilistic behavior of a Markov process $X(t)$ over intervals is defined by the interval transition probability matrix V:

$\mathbf{V}=\left[v_{i j}\right], \quad$ where $v_{i j}=P\left[X\left(t_{1}\right)=j \mid X\left(t_{0}\right)=i\right]$

The interval transition probabilities matrix $\mathbf{V}$ of the Markov process satisfies the Kolmogorov differential equation, and thus can be linked with transition intensity matrix $\mathbf{A}$ as following:

$\mathbf{V}\left(t_{1}-t_{0}\right)=e^{\left(t_{1}-t_{0}\right) \mathbf{A}}$,

If the state probability at location $t_{0}$ is known, denoted as row vector $\vec{s}\left(t_{0}\right)$, one can infer the state probability at location $t_{1}$ through the following equation:

$\vec{s}\left(t_{1}\right)=\vec{s}\left(t_{0}\right) \mathbf{V}\left(t_{1}-t_{0}\right)$

As presented above, a Markov process is totally determined by its transition intensity matrix. In general, the estimation of $p_{i j}$ and $c_{i}$ can be accomplished by either subjective assessment or statistical procedure. If the geology profile for a certain project and the geology map for a large area are available, $c_{i}$ can be estimated by computing the inverse of average length of each state $i$, while $p_{i j}$ can be estimated by computing the ratio between the number of transitions from states $i$ to $j$ and the total number of transitions out of state $i$. As presented in next section, the prior transition intensity matrix obtained from geology map could be updated dynamically when new information is available.

\subsection{Bayesian updating for transition intensity matrix}

The likelihood matrix $\mathbf{L}$ for a particular exploration method at a certain location is defined as:

$\mathbf{L}=\left[l_{j k}\right], \quad$ where $l_{j k}=P\left[Y\left(t_{b}\right)=k \mid X\left(t_{b}\right)=j\right]$ 
In the above, $Y\left(t_{b}\right)$ denotes the observation result at location $t_{b}$ for geological parameter $X\left(t_{b}\right)$, $l_{j k}$ denotes the likelihood of observation result $k$ given that the true parameter state is $j$. The likelihood matrix $\mathbf{L}$ is estimated by subjective assessment, which reflects the engineers' confidence about the observation results. In general, the likelihood matrix varies for different exploration methods. For example, the likelihood matrix for boring hole is close to an identity matrix, because samples are often examined through several laboratory tests and the observation results are highly reliable. On the contrary, the likelihood matrix for face logging is diagonally dominant, since in-situ measurements are often less reliable than laboratory tests.

When new geological information is available, e.g. new face logging is observed, the interval transition probability matrix should be updated sequentially according to this new information. Suppose that new tunnel face $t_{f}$ is excavated towards the direction of a known boring hole $t_{q}$. Considering the interval from location $t_{f}$ to location $t_{q}$, the prior interval transition probability matrix $\mathbf{V}\left(t_{q}-t_{f}\right)$ is calculated by Eq. 4, using the prior transition intensity matrix $\mathbf{A}$. According to Bayes' theorem, the posterior interval transition probability matrix $\mathbf{V}^{\prime}\left(t_{q}-t_{f}\right)$ is updated by the following equation, when a certain observation result $k$ is revealed at location $t_{f}$.

$$
\mathbf{V}^{\prime}=\left[v_{i j}^{\prime}\right], \quad \text { where } v_{i j}^{\prime}=\frac{v_{i j} l_{j k}}{\sum_{j=1}^{n} v_{i j} l_{j k}} \text { for a certain observation result } k \text { at new location }
$$

Then the posterior transition intensity matrix A', which reflects the "average" transition probability and the "average" transition intensity coefficient within the range between location $t_{q}$ and $t_{f}$, can be calculated by the following:

$$
\mathbf{A}^{\prime}=\frac{\log \mathbf{V}^{\prime}\left(t_{q}-t_{f}\right)}{t_{q}-t_{f}}
$$

Notice that the updating procedure should be constrained locally within the range between location $t_{f}$ (the tunnel face) and location $t_{q}$ (the known boring hole ahead of face). When tunnel face advances and new face logging is observed continuously, the updating procedure is the same just as shown in Eq. 7 and Eq. 8. Therefore, the state probability for that geological parameter ahead of tunnel face can be predicted dynamically with the face advancing.

\subsection{Ground condition as a complex geological parameter}

In practice, ground condition is often classified into several grades according to the simultaneous characteristics of several geological parameters of interest. Therefore, a geology table should be defined here to specify which kinds of 
geological parameter combination belong to which grade of ground condition. Then regarding ground condition as a complex geological parameter, when the probabilistic characteristic of each single geological parameter is determined by the Markov process presented above, the probabilistic characteristic of ground condition along the tunnel alignment also can be determined. This procedure will be illustrated in an application case study in next section.

\section{Application and discussion}

\subsection{Outline of Chuangshi Tunnel}

The Chuangshi Tunnel in Songjian expressway located in northern Fujian Province of China is a separate road tunnel with 4 lanes in up-line \& down-line. The geology profile of Chuangshi Tunnel, as illustrated in Fig. 1, was obtained from surface geophysical prospecting and subsurface boring exploration (TPDIFP, 2009). During the design phase, this geology profile was used to classify the ground condition and determine the excavation method and support system. The 764m long tunnel was constructed by the New Austrian Tunneling Method. The top-heading excavation method was employed consistently throughout the whole tunnel, and the excavation length of each cycle ranged from $1 \mathrm{~m}$ to $3 \mathrm{~m}$ according to different ground conditions. The installation of support system also depended on the different ground conditions. For the ground condition of grade III, only local rock bolts and shotcrete lining were used to help the ground stabilize itself. For the ground condition of grade IV, pattern rock bolts, steel arches and shotcrete lining were used. Moreover, forepoling prior to excavation (including pipe spiling and grouting) was employed for the ground condition of grade V. The schematic representations of excavation cycle and support system are illustrated in Fig. 2.

\subsection{Construction monitoring of Chuangshi Tunnel}

The construction of Chuangshi Tunnel began in Jan. 2010 and finished in Jul. 2011, and the construction monitoring (including tunnel convergence monitoring, face logging and advance geology prospecting) was carried out by the authors' workgroup. The tunnel was excavated from two portals, and the two faces met in the stake of ZK47+496. According to different ground conditions, the convergence monitoring section was erected every $15 \mathrm{~m} \sim 30 \mathrm{~m}$, the face logging was conducted every $5 \mathrm{~m} \sim 10 \mathrm{~m}$ and the advance geology prospecting by TSP203 was conducted every $120 \mathrm{~m} \sim 150 \mathrm{~m}$. 
During the construction phase, more detailed geology information ahead of the face was inferred by hard method (advanced geological prospecting by TSP203) and soft method (Markovian geology prediction approach based on face logging). The case study of Markovian geology prediction approach in Chuangshi Tunnel is expatiated in this article, and the object is to predict the ground conditions ahead of face in a probabilistic way based on face logging.

\subsection{Four geological parameters}

Many rock mass classification systems have been proposed by former researchers, and a recent review on this issue was summarized by Tzamos and Sofianos (2007). According to Chinese Codes for Design of Road Tunnel (2004) and Chinese Standard for Engineering Classification of Rock Masses (1994), a BQ system is employed for the classification of rock mass (see details in Appendix A).

In accord with the $B Q$ system and considering the geology information obtained from subsurface boring exploration, four single geological parameters are selected and described by independent Markov processes. Rock hardness (H) corresponds to the parameter of $R_{c}$ in $B Q$ system. Index 1 or index 2 denotes that the intact rock revealed in that face is relatively hard or relatively soft. Joint intensity (I) partially corresponds to the parameter of $K_{v}$ in $B Q$ system. Index 1, index 2 or index3 denotes that the joint number accounted in that face is relatively more, medium or relatively less. Joint quality (Q) partially corresponds to the parameters of $K_{v}$ and $K_{2}$ in $B Q$ system, which takes the joint openness, the joint length, the joint infilling and the occurrence of major joint (if any) into account. Index 1, index 2 or index3 denotes that the joint quality revealed in that face is relatively good, medium or relatively poor. Water content (C) corresponds to the parameter of $K_{1}$ in $B Q$ system. Index 1 or index 2 denotes that the revealed tunnel face is relatively dry or relatively humid.

Taking the tunnel face at ZK57+608 for example, the face logging is illustrated in Fig. 3 and detailed description was recorded in a specified table (not given here). According the definitions of rock hardness, joint intensity, joint quality and water content, and due to the engineers' qualitative assessment, the geology information at that face was simplified as $(1,2,2,1)$. Notice that, the selection and definition for geology parameter are case by case, and the indices merely denote the relative relationships for the descriptions of geology parameters.

\subsection{Geology table}

According to the definitions of four geology parameters, a total of 36 possible combinations (i.e. geology vector) 
can be defined. Then these 36 geology vectors are classified into three ground conditions as shown in Table 1 . Notice that, the definition of geology table is also case by case. It is partially referred to Chinese codes (2004) and Chinese standards (1994), and partially subjected to engineers’ experience for Chuangshi Tunnel.

\subsection{Prior transition intensity matrixes}

The prior transition intensity matrixes for these four geological parameters are listed in Table 2 . They are mainly referred to the geology profile of Chuangshi Tunnel, and also partially referred to the geology map in a larger area. (see details in Section 2.1)

\subsection{Likelihood matrixes}

The likelihood matrixes that reflect the engineers' confidence about the observation results are generally different from location to location. For simplification, however, they are assumed constant throughout the tunnel alignment. The likelihood matrixes for each single geology parameter are listed in Table 3, which are subjectively estimated from the engineers’ past experience (not constrained in the engineering instance of Chuangshi Tunnel ).

\subsection{Dynamic prediction of ground condition}

The tunnel face remained at location ZK47+280 ( $18^{\text {th }}$ May), and moved towards location ZK47+448 (where a known boring hole had been revealed before construction) during the following three months. Take the segment between these two locations as an application example.

The observation results for location 448 from boring hole BH3 are $(2,2,1,1)$, thus the state probability of each geological parameter can be found directly from its corresponding likelihood matrix. Then the state probability of a particular GV is the product of the state probabilities of all parameters related to that GV. Then the state probability of a particular GC is the sum of the state probabilities of all geology vectors belonged to that GC. As a summary, the state probabilities of four geological parameters and ground condition are listed in Table 4.

The prior interval transition probability matrix between location 448 and location 280 can be computed by Eq. 4 with the prior transition intensity matrix. The observation results for location 280 from face logging are $(1,1,1,2)$, and this new information is used to update the interval transition probability matrix according to Eq. 7. Then the posterior transition intensity matrix within the range between location 448 and location 280 can be computed by Eq. 8 . As a summary, the posterior transition intensity matrixes for those four geological parameters are listed in Table 5. 
For any particular location $t_{x}$ within these two locations, the state probability of each geological parameter can be computed by Eq. 4 and Eq. 5, where the posterior transition intensity matrixes instead of the prior ones are used in the calculation. Then the state probability of ground condition at location $t_{x}$ can also be calculated by the similar arithmetic operations with the ones at location 448 .

As a summary, the prediction of ground condition between location 448 and location 228 is delineated in Fig. 4 . The areas below asterisk-line and above dotted-line denote the state probabilities of grade V and grade III, respectively. The area between these two lines denotes the probabilities of grade IV. If the state probability of a particular ground condition is much more significant than others (i.e. greater than 0.5), the location is marked with the corresponding label. For comparison, the real ground condition after excavation (observed by face logging afterwards) is also listed in the top of Fig. 4.

When the tunnel face advanced to location ZK47+328 $\left(28^{\text {th }} \mathrm{Jun}\right)$, similar calculations can be carried out to predict the ground condition between location 448 and location 328, as depicted in Fig. 5. If the state probabilities of two particular ground conditions are nearly equivalent, the location is marked with two corresponding labels. Similarly, Fig. 6 shows the perdition of ground condition, when the tunnel face advanced to location ZK47+376 (18 $\left.{ }^{\text {th }} \mathrm{Jul}\right)$. Generally speaking, the prediction results fit the real ground conditions well, especially for a short range ahead of tunnel face.

\subsection{Some discussions and comments}

In general, the Markovian geology prediction approach can be regarded as a good complement to the advanced geophysical prospecting during the construction phase, because it can dynamically predict the ground condition in a short range ahead of face with very low cost. More importantly, this approach provides the prediction of ground condition in a quantitative (probabilistic) way, which can further be used to estimate the project cost and period, evaluate the geology-related risk and help the decision-making during construction phase (Haas and Einstein, 2002; Min et al., 2008).

In fact, a geological parameter that doesn’t obey the continuous-space discrete-state Markov process also can be included in the proposed geology prediction approach. For example, the cover depth, a key geological parameter for ground condition classification in deep tunnels, is a continuous-space continuous-state process with a deterministic 
(not random) distribution. This continuous-state parameter can be divided into several discrete states (e.g. very deep, deep, medium), so that the state probability of cover depth for any location can be assigned directly and will not be updated. Then the cover depth can also be involved in the ground condition classification just as other geology parameters. Therefore, the proposed approach can be regarded as a framework, which can cover many types of geological parameter to predict the ground condition in a quantitative (probabilistic) way.

Besides the merits presented above, the proposed geology prediction approach also has some shortages. Essentially, this approach assumes that the ground condition changes gradually and monotonically between two observation locations. Take the segment between ZK47+536 (a known boring hole) and ZK47+704 (tunnel face in $12^{\text {th }}$ Apr) as another example. The observation results and the prediction results are depicted in Fig. 7, where the prediction results fail to agree with the real ground conditions in the middle of segment. The ground conditions at these two observation locations (one near the portal and another within the fault) are classified as grade V. But there exists a small segment of ground condition grade IV between these two observation locations. Then this approach fails to deal with this case when non-monotonic changing ground conditions occur. Fortunately, when tunnel face advances to location ZK47+640 (30 ${ }^{\text {th }}$ May) and new face logging is observed, the prediction results again fit the real ground conditions well as shown in Fig. 8.

\section{Conclusions}

The Markovian geology prediction approach and its application case study are presented in this article. Each single geological parameter is assumed to be described by a continuous-space discrete-state Markov random process, where the transition intensity matrix is initially determined by the known geology information before excavation and then Bayesian updated according to the newly revealed information during construction phase. Then the state probability distribution of each geological parameter between two locations (i.e. a tunnel face and a known boring hole) can be inferred. Then the state probability distribution of ground condition can be calculated by the permutation and combination of each single geological parameter according to a specific defined geology table.

The application case study on Chuangshi Tunnel shows that this approach can dynamically predict the ground conditions with very low cost, and the prediction results fit the real ground conditions well especially for a short range 
ahead of face. On the other hand, the implicit assumption that the ground conditions change gradually and monotonically make it awkward to deal with the complex case when non-monotonic changing ground conditions occur.

In general, the Markovian geology prediction approach can be regarded as a good complement to the advanced geophysical prospecting approach during the construction phase. Moreover, it can further be used to estimate the project cost and period, evaluate the geology-related risk and help the decision-making during the construction phase of mountain tunnels.

\section{Appendix A: BQ system for rock mass classification}

Firstly, the basic quality index of rock mass $B Q$ is related to the uniaxial compression strength $R_{c}$ and coefficient of integrity $K_{v}$ by the following equation.

$$
B Q=90+3 R_{c}+250 K_{v}
$$

$R_{c}$ (in unit of MPa) can be obtained by standard uniaxial compression test in laboratory, or related to in-situ point load strength $I_{s(50)}$ by Eq.A2. $K_{v}$ (dimensionless) can be related to the p-wave velocity in rock mass $V_{p m}$ and the p-wave velocity in intact rock $V_{p r}$ as shown in Eq.A3.

$$
\begin{aligned}
& R_{c}=22.82 I_{s(50)}^{0.75} \\
& K_{v}=\left(V_{p m} / V_{p r}\right)^{2}
\end{aligned}
$$

If the experimental data are not available, $R_{c}$ and $K_{v}$ can also be estimated by qualitative means. In accord with two specified empirical tables (not listed here), the engineers could estimate the $R_{c}$ value empirically according to the rock type and hammer rebound, and estimate the $K_{v}$ value empirically according to joint number in unit area, joint openness, and joint infilling.

Secondly, the modified quality index of rock mass $[B Q]$ is calculated by the following equation.

$$
[B Q]=B Q-100\left(K_{1}+K_{2}+K_{3}\right)
$$

The dimensionless correction factors $K_{1}, K_{2}$ and $K_{3}$ are related to the inflow of underground water, the occurrence of major joint, the level of in-situ stresses. In accord with three specified empirical tables (not listed here), these 
factors are estimated empirically according to the engineers' assessment.

Finally, the rock mass is classified according to its $[B Q]$ value by the following Table A1.

\section{Acknowledgement}

The research project is sponsored by the Scientific Research Foundation for Returned Overseas Chinese Scholars (Grant No. LXKQ0904) and National Natural Science Foundation of China (Grant No. 51008082). The comments from Prof. Hongwei Huang in Tongji University is also appreciated.

\section{Reference}

Alimoradi A., Moradzadeh A., et al., 2008. Prediction of geological hazardous zones in front of a tunnel face using TSP-203 and artificial neural networks. Tunn. Undergr. Sp. Tech., 23, 711-717.

Ching J., Chen Y., 2007. Transitional Markov chain Monte Carlo method for Bayesian model updating, model class selection and model averaging. J. Engng. Mech., ASCE, 133, 816-832.

Felletti F., Beretta G., 2009. Expectation of boulder frequency when tunneling in glacial till: A statistical approach based on transition probability. Engineering Geology, 108, 43-53.

Haas C., Einstein H., 2002. Updating the Decision Aids for Tunneling. J. Constr. Engng. Management, ASCE, 128, 40-48.

Ioannou P., 1987. Geologic prediction model for tunneling. J. Constr. Engng. Management, ASCE, 113, 569-590.

Ioannou P., 1989. Dynamic probabilistic decision processes. J. Constr. Engng. Management, ASCE, 115, 237-257.

Jeon J., Martin C., et al., 2005. Predicting ground conditions ahead of the tunnel face by vector orientation analysis. Tunn. Undergr. Sp. Tech., 20, 344-355.

Lau S., Lu M., Ariaratnam S., 2010. Applying radial basis function neural networks to estimate next-cycle production rates in tunnelling construction. Tunn. Undergr. Sp. Tech. 25, 357-365.

Leu S., Adi T., 2011. Microtunneling decision support system using Neural-Autoregressive Hidden Markov Model. Expert Systems with Applications, 38, 5801-5808.

Leu S., Adi T., 2011. Probabilistic prediction of tunnel geology using a Hybrid Neural-HMM. Engineering Applications of Artificial Intelligence, 38, 658-665. 
Min S., Kim T., et al., 2008. Design and construction of a road tunnel in Korea including application of the Decision Aids for Tunneling. Tunn. Undergr. Sp. Tech., 23, 91-102.

Ministry of Transportation of P.R. China, 2004. Chinese codes for design of road tunnel JTGD70-2004. (in Chinese).

Ministry of Urban-Rural Development of P.R. China, 1994. Chinese standard for engineering classification of rock masses GB50218-1994 (in Chinese).

Miranda T., Correia A., Sousa L., 2009. Bayesian methodology for updating geomechanical parameters and uncertainty quantification. Int. J. Rock Mech. Mining Sci., 46, 1144-1153.

Transportation Planning and Design Institute of Fujian Province, 2009. Design documents for Songjian expressway in Fujian Province (in Chinese).

Tzamos S., Sofianos A., 2007. A correlation of four rock mass classification systems through their fabric indices. Int. J. Rock Mech. Mining Sci., 44, 477-495.

\section{List of figures}

Fig. 1 The geology profile of Chuangshi Tunnel (during design phase).

Fig. 2 Schematic representations of a) excavation cycle and b) support system of Chuangshi tunnel.

Fig. 3 Face logging of Chuangshi tunnel at the stake of ZK57+608.

Fig.4 Ground condition prediction between boring hole (448) and tunnel face (280).

Fig.5 Ground condition prediction between boring hole (448) and tunnel face (328).

Fig.6 Ground condition prediction between boring hole (448) and tunnel face (376).

Fig.7 Ground condition prediction between boring hole (536) and tunnel face (704).

Fig.8 Ground condition prediction between boring hole (536) and tunnel face (640).

\section{List of tables}

Table 1 The geology table for Chuangshi tunnel. 
Table 2 The prior transition intensity matrixes of four geological parameters.

Table 3 The likelihood matrixes of four geological parameters.

Table 4 State probabilities at location 448.

Table 5 The posterior transition intensity matrixes (after updating at location 280).

Table A1 Ground condition classification according to $[B Q]$ value. 


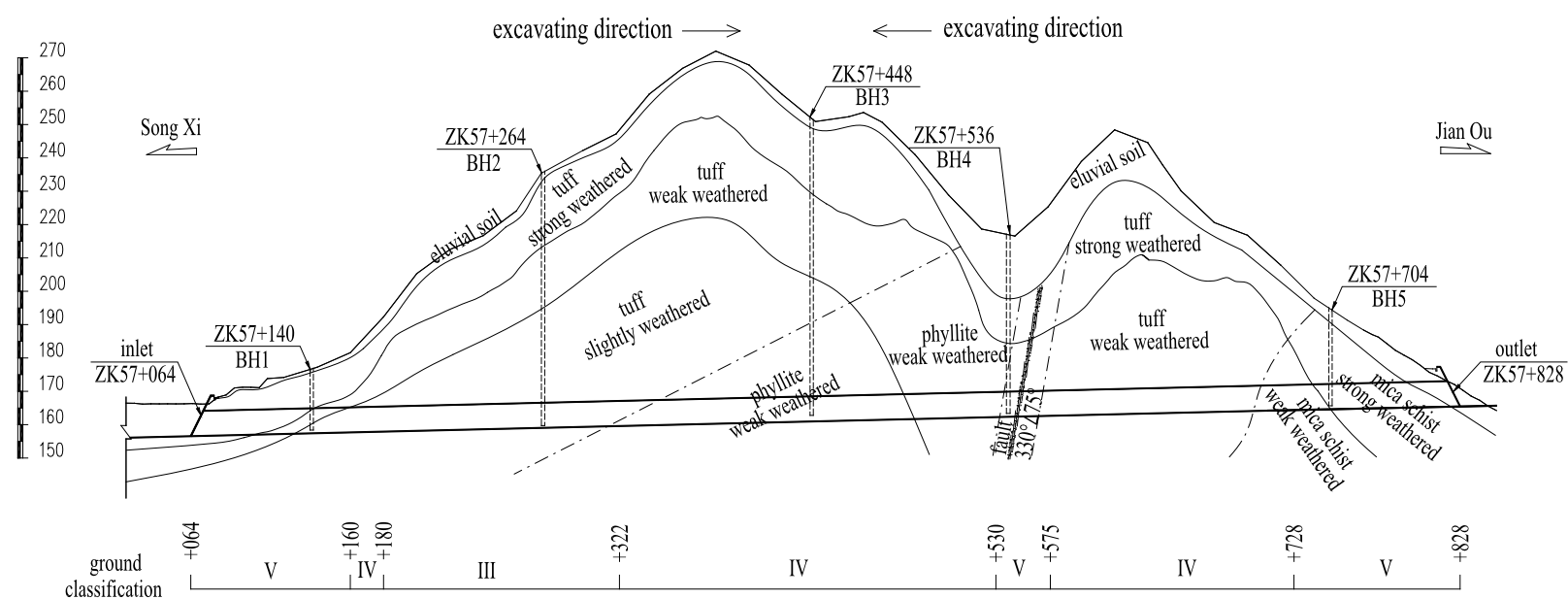

Fig. 1 The geology profile of Chuangshi tunnel (during design phase).
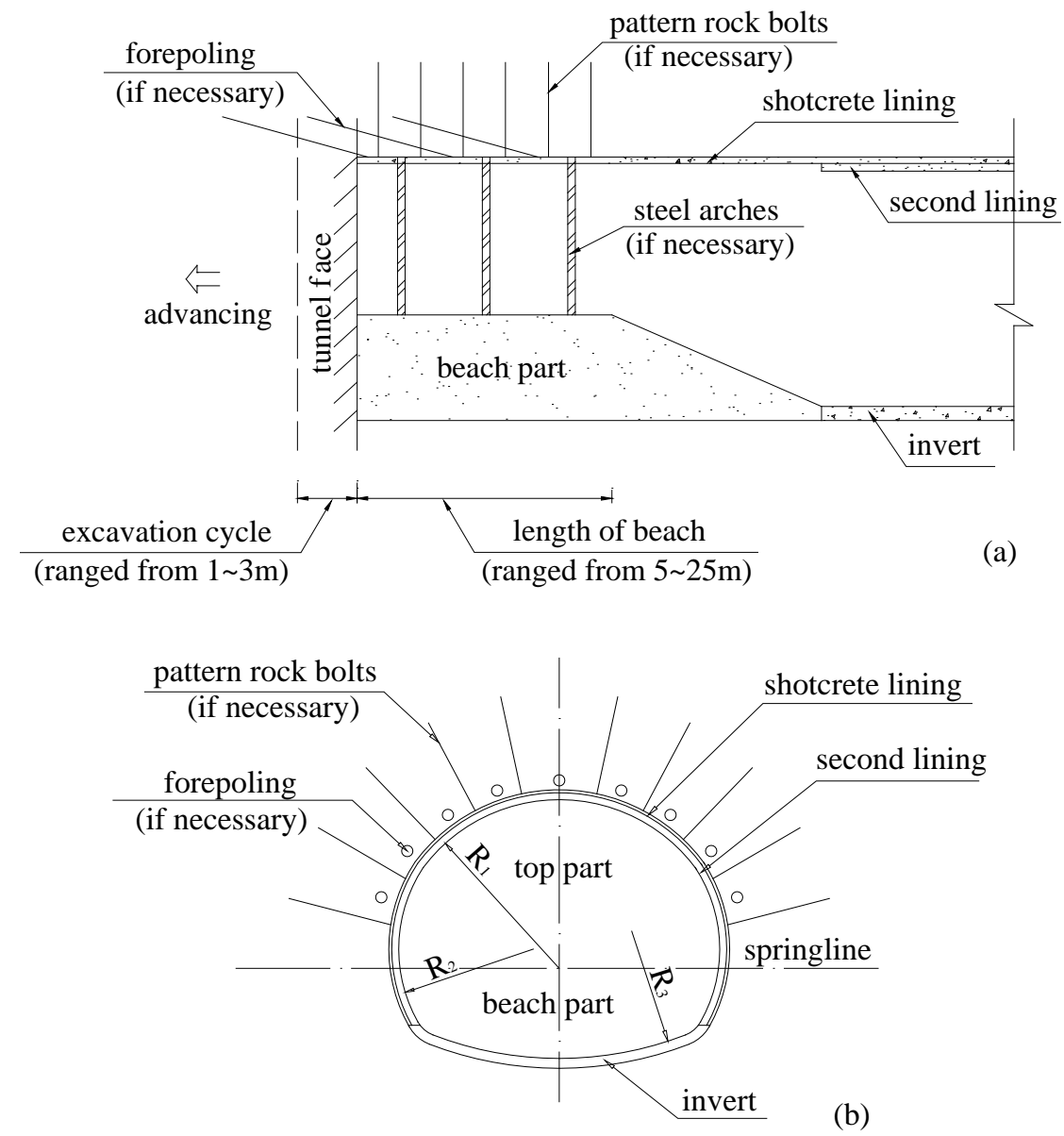

Fig. 2 Schematic representations of a) excavation cycle and b) support system of Chuangshi tunnel. 


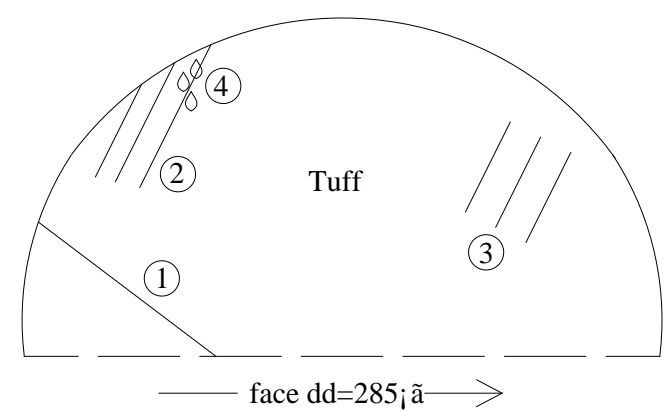

Fig. 3 Face logging of Chuangshi tunnel at the stake of ZK57+608.

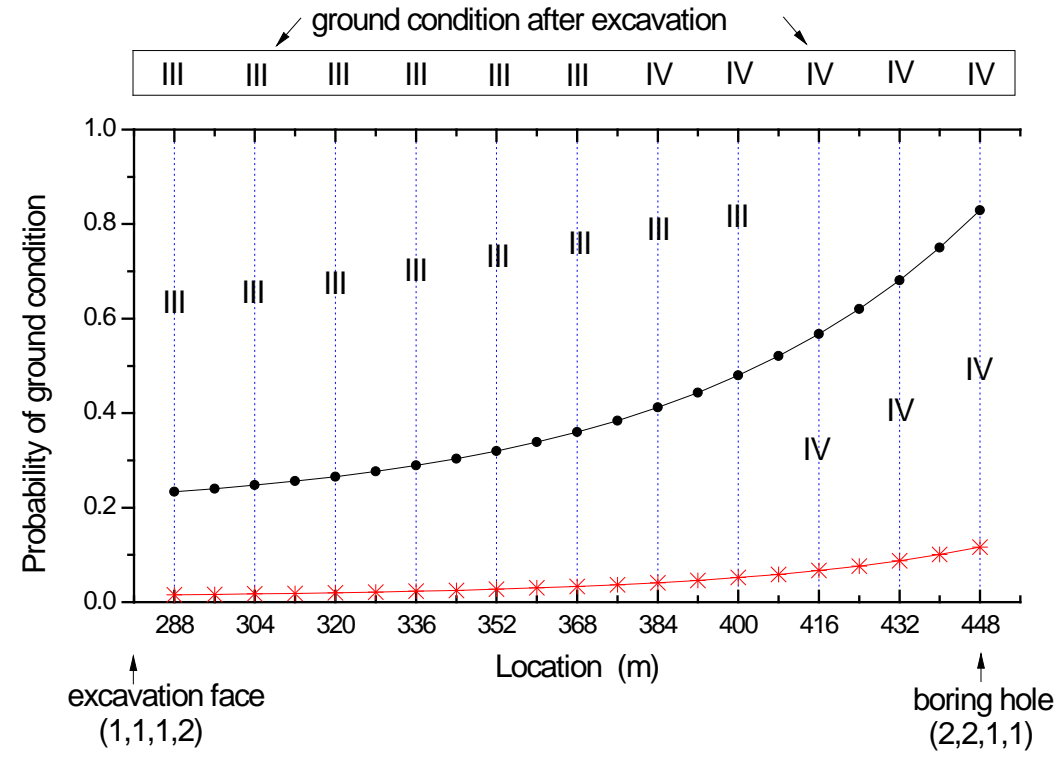

Fig.4 Ground condition prediction between boring hole (448) and tunnel face (280).

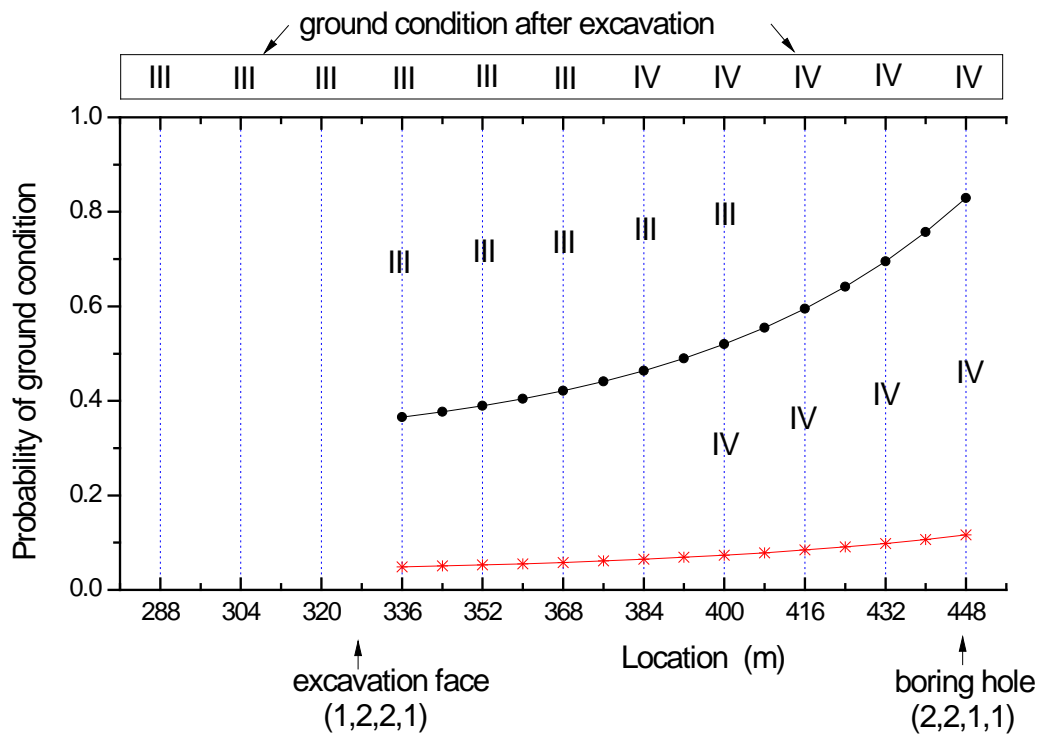

Fig.5 Ground condition prediction between boring hole (448) and tunnel face (328). 


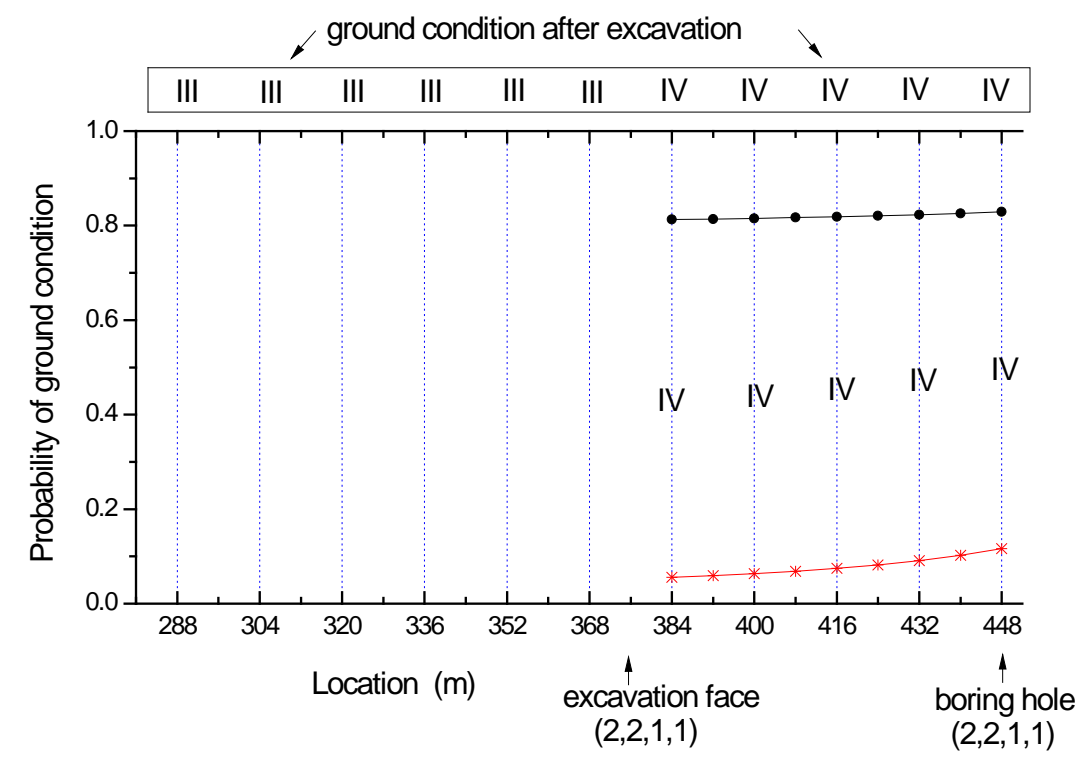

Fig.6 Ground condition prediction between boring hole (448) and tunnel face (376).

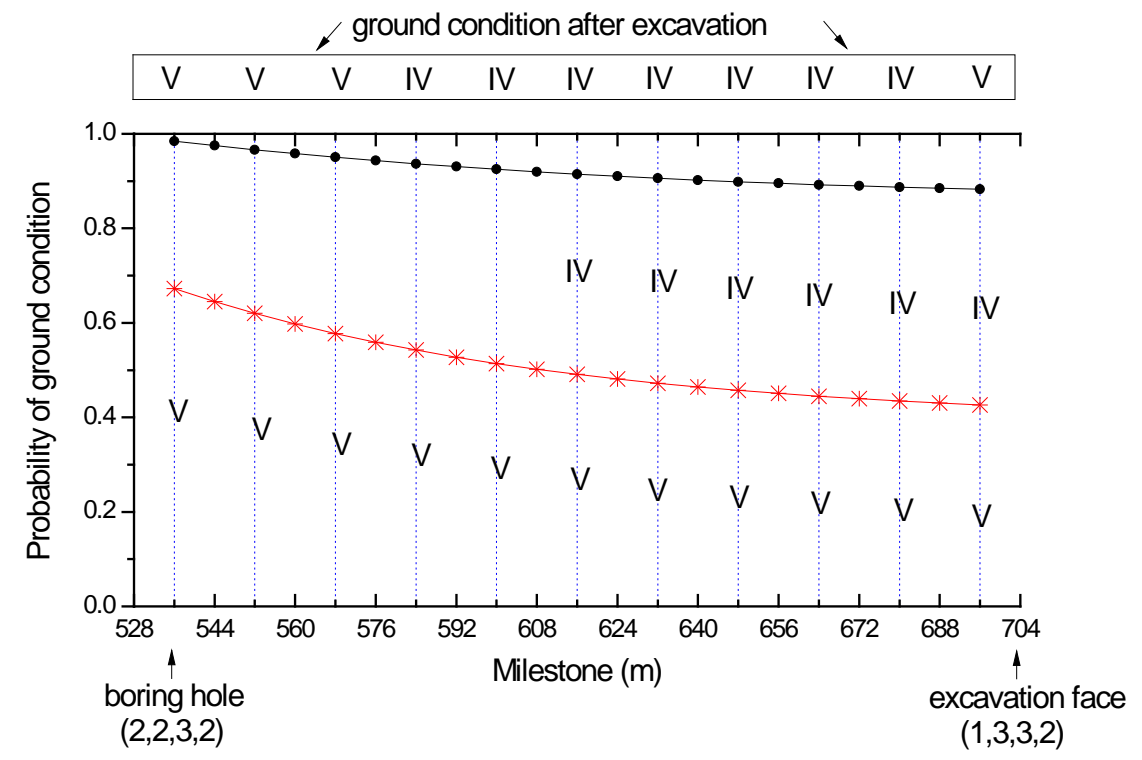

Fig.7 Ground condition prediction between boring hole (536) and tunnel face (704). 


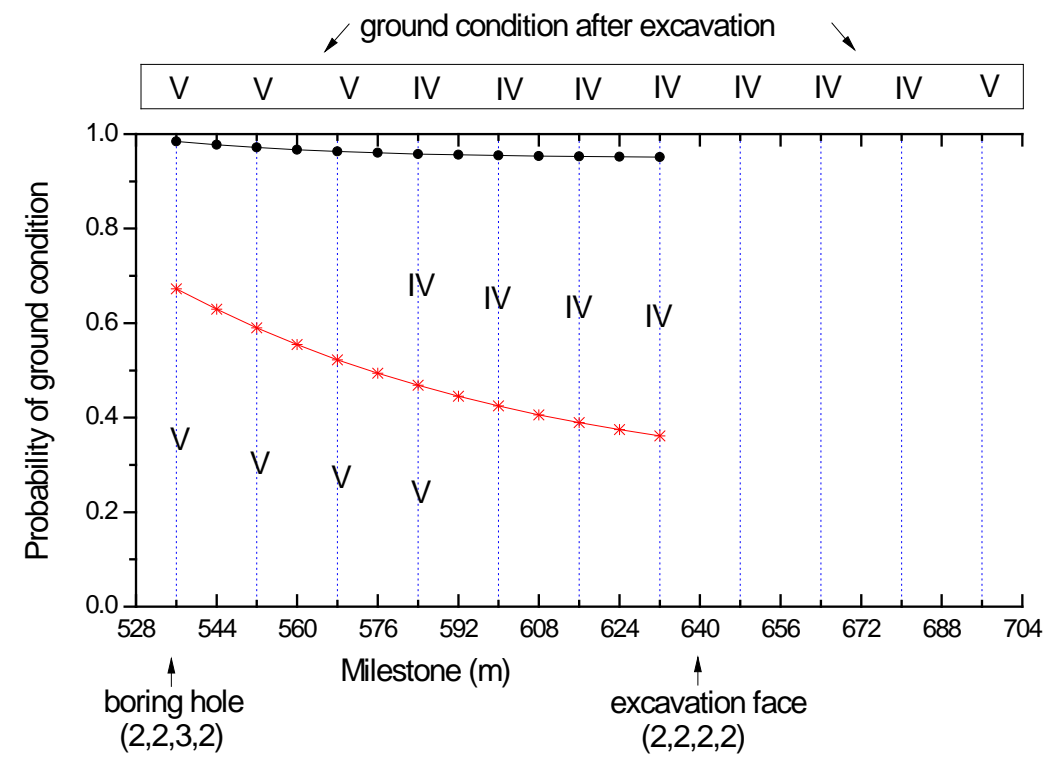

Fig.8 Ground condition prediction between boring hole (536) and tunnel face (640). 
Table 1 The geology table for Chuangshi tunnel.

\begin{tabular}{|c|c|c|c|c|c|}
\hline \multirow{2}{*}{$\begin{array}{l}\text { ground } \\
\text { condition } \\
\text { (GC) }\end{array}$} & \multirow{2}{*}{$\begin{array}{l}\text { geology vector } \\
\text { (GV) }\end{array}$} & \multicolumn{4}{|c|}{ geological parameter } \\
\hline & & $(\mathrm{H})$ & (I) & $(\mathrm{Q})$ & (W) \\
\hline \multirow{10}{*}{$\begin{array}{c}\text { index } 1 \\
\text { (grade III) }\end{array}$} & GV01 & 1 & 1 & 1 & 1 \\
\hline & GV02 & 1 & 1 & 1 & 2 \\
\hline & GV03 & 1 & 2 & 1 & 1 \\
\hline & GV04 & 1 & 2 & 1 & 2 \\
\hline & GV05 & 1 & 3 & 1 & 1 \\
\hline & GV06 & 1 & 1 & 2 & 1 \\
\hline & GV07 & 1 & 1 & 2 & 2 \\
\hline & GV08 & 1 & 2 & 2 & 1 \\
\hline & GV09 & 1 & 1 & 3 & 1 \\
\hline & GV10 & 2 & 1 & 1 & 1 \\
\hline \multirow{15}{*}{$\begin{array}{c}\text { index } 2 \\
\text { (grade IV) }\end{array}$} & GV11 & 1 & 3 & 1 & 2 \\
\hline & GV12 & 1 & 2 & 2 & 2 \\
\hline & GV13 & 1 & 3 & 2 & 1 \\
\hline & GV14 & 1 & 3 & 2 & 2 \\
\hline & GV15 & 1 & 1 & 3 & 2 \\
\hline & GV16 & 1 & 2 & 3 & 1 \\
\hline & GV17 & 2 & 1 & 1 & 2 \\
\hline & GV18 & 2 & 2 & 1 & 1 \\
\hline & GV19 & 2 & 2 & 1 & 2 \\
\hline & GV20 & 2 & 3 & 1 & 1 \\
\hline & GV21 & 2 & 1 & 2 & 1 \\
\hline & GV22 & 2 & 1 & 2 & 2 \\
\hline & GV23 & 2 & 2 & 2 & 1 \\
\hline & GV24 & 2 & 2 & 2 & 2 \\
\hline & GV25 & 2 & 1 & 3 & 1 \\
\hline \multirow{11}{*}{$\begin{array}{c}\text { index } 3 \\
\text { (grade V) }\end{array}$} & GV26 & 1 & 2 & 3 & 2 \\
\hline & GV27 & 1 & 3 & 3 & 1 \\
\hline & GV28 & 1 & 3 & 3 & 2 \\
\hline & GV29 & 2 & 3 & 1 & 2 \\
\hline & GV30 & 2 & 3 & 2 & 1 \\
\hline & GV31 & 2 & 3 & 2 & 2 \\
\hline & GV32 & 2 & 1 & 3 & 2 \\
\hline & GV33 & 2 & 2 & 3 & 1 \\
\hline & GV34 & 2 & 2 & 3 & 2 \\
\hline & GV35 & 2 & 3 & 3 & 1 \\
\hline & GV36 & 2 & 3 & 3 & 2 \\
\hline
\end{tabular}


Table 2 The prior transition intensity matrixes of four geological parameters.

\begin{tabular}{|c|c|c|c|c|c|c|c|c|c|}
\hline \multicolumn{2}{|c|}{ for rock hardness: $\mathbf{A}^{\mathrm{H}}$} & \multicolumn{3}{|c|}{ for joint intensity: $\mathbf{A}^{\mathrm{I}}$} & \multicolumn{3}{|c|}{ for joint quality: $\mathbf{A}^{\mathrm{Q}}$} & \multicolumn{2}{|c|}{ for water content: $\mathbf{A}$} \\
\hline \multirow{3}{*}{$\begin{array}{c}-0.0090 \\
0.0041\end{array}$} & \multirow{3}{*}{$\begin{array}{r}0.0090 \\
-0.0041\end{array}$} & -0.0027 & 0.0018 & 0.0009 & -0.0053 & 0.0036 & 0.0018 & \multirow{3}{*}{$\begin{array}{r}-0.0080 \\
0.0089\end{array}$} & \multirow{3}{*}{$\begin{array}{r}0.0080 \\
-0.0089\end{array}$} \\
\hline & & 0.0024 & -0.0048 & 0.0024 & 0.0025 & -0.0050 & 0.0025 & & \\
\hline & & 0.0026 & 0.0054 & -0.0080 & 0.0026 & 0.0054 & -0.0080 & & \\
\hline
\end{tabular}

Table 3 The likelihood matrixes of four geological parameters.

\begin{tabular}{|c|c|c|c|c|c|c|c|c|c|c|}
\hline & for rock & Irdness: $\mathbf{L}^{\mathrm{H}}$ & for jc & t inten & ty: $\mathbf{L}^{\mathrm{I}}$ & for jc & th qual & $\mathbf{L}^{\mathrm{Q}}$ & for water & ntent: $\mathbf{L}^{\mathrm{C}}$ \\
\hline \multirow{3}{*}{$\begin{array}{c}\text { for surface boring } \\
\text { prospecting }\end{array}$} & \multirow{3}{*}{$\begin{array}{l}0.95 \\
0.05\end{array}$} & \multirow{2}{*}{0.05} & 0.8 & 0.15 & 0.05 & 0.8 & 0.15 & 0.05 & \multirow{2}{*}{0.9} & \multirow{2}{*}{0.1} \\
\hline & & & \multirow{2}{*}{$\begin{array}{l}0.15 \\
0.05\end{array}$} & 0.7 & 0.15 & 0.15 & 0.7 & 0.15 & & \\
\hline & & 0.95 & & 0.15 & 0.8 & 0.05 & 0.15 & 0.8 & 0.1 & 0.9 \\
\hline \multirow{3}{*}{ for face logging } & \multirow{3}{*}{$\begin{array}{l}0.9 \\
0.1\end{array}$} & \multirow{3}{*}{$\begin{array}{l}0.1 \\
0.9\end{array}$} & 0.7 & 0.25 & 0.05 & 0.7 & 0.25 & 0.05 & \multirow{3}{*}{$\begin{array}{l}0.7 \\
0.3\end{array}$} & \multirow{3}{*}{$\begin{array}{l}0.3 \\
0.7\end{array}$} \\
\hline & & & 0.25 & 0.5 & 0.25 & 0.25 & 0.5 & 0.25 & & \\
\hline & & & 0.05 & 0.25 & 0.7 & 0.05 & 0.25 & 0.7 & & \\
\hline
\end{tabular}

Table 4 State probabilities at location 448.

\begin{tabular}{|l|lll|}
\hline & index 1 & index 2 & index 3 \\
\hline rock hardness (H) & 0.050 & 0.950 & \\
joint intensity (I) & 0.150 & 0.700 & 0.150 \\
joint quality (Q) & 0.800 & 0.150 & 0.050 \\
water content (C) & 0.900 & 0.100 & \\
\hline ground condition (GC) & 0.148 & 0.778 & 0.074 \\
\hline
\end{tabular}

Table 5 The posterior transition intensity matrixes (after updating at location 280).

\begin{tabular}{|c|c|c|c|c|c|c|c|c|c|}
\hline \multicolumn{2}{|c|}{ for rock hardness: $\mathbf{A}^{\mathbf{H}}$} & \multicolumn{3}{|c|}{ for joint intensity: $\mathbf{A}^{, \mathrm{I}}$} & \multicolumn{3}{|c|}{ for joint quality: $\mathbf{A}^{\mathbf{Q}}$} & \multicolumn{2}{|c|}{ for water content: $\mathbf{A}^{, \mathrm{C}}$} \\
\hline \multirow{3}{*}{$\begin{array}{l}-0.0025 \\
0.0129\end{array}$} & \multirow{3}{*}{$\begin{array}{r}0.0025 \\
-0.0129\end{array}$} & -0.0010 & 0.0009 & 0.0001 & -0.0022 & 0.0019 & 0.0003 & \multirow{3}{*}{$\begin{array}{c}-0.0121 \\
0.0056\end{array}$} & \multirow{3}{*}{$\begin{array}{c}0.0121 \\
-0.0056\end{array}$} \\
\hline & & 0.0054 & -0.0063 & 0.0009 & 0.0054 & -0.0062 & 0.0008 & & \\
\hline & & 0.0091 & 0.0104 & -0.0194 & 0.0089 & 0.0102 & -0.0191 & & \\
\hline
\end{tabular}

Table A1 Ground condition classification according to [BQ] value.

\begin{tabular}{|c|cccccc|}
\hline modified quality index of rock mass $[B Q]$ & $>550$ & $550 \sim 451$ & $450 \sim 351$ & $350 \sim 251$ & $\leq 250$ \\
\hline ground condition & I & II & III & IV & V \\
\hline
\end{tabular}

